\title{
Relationship of renal size to nephropathy in Type 1 (insulin-dependent) diabetes
}

\author{
E. N.Ellis ${ }^{1}$, M.W.Steffes ${ }^{2}$, F.C. Goetz ${ }^{3}$, D. E. R. Sutherland ${ }^{4}$ and S. M. Mauer ${ }^{1}$ \\ Departments of Pediatrics ${ }^{1}$, Laboratory Medicine and Pathology ${ }^{2}$, Internal Medicine ${ }^{3}$ and Surgery ${ }^{4}$, University of Minnesota School of Medicine, \\ Minneapolis, Minnesota, USA
}

\begin{abstract}
Summary. Thirty-five patients with Type 1 (insulin-dependent) diabetes mellitus and 90 normal subjects had renal size (renal area index) determined by X-ray and also had examination of renal biopsies by light and electron microscopy. Renal area index of $206 \pm 32 \mathrm{~cm}^{2} / 1.73 \mathrm{~m}^{2}($ mean $\pm \mathrm{SD})$ in the Type 1 diabetic patients exceeded that in the normal subjects $(180 \pm$ $\left.25 \mathrm{~cm}^{2} / 1.73 \mathrm{~m}^{2}, p<0.001\right)$. In the diabetic patients, the renal area index correlated with creatinine clearance $(r=+0.43$, $p<0.05$ ), but did not correlate with urinary albumin excretion, or the electron microscopic measurements of percentage
\end{abstract}

total mesangium and glomerular basement membrane width. In diabetic patients with clinical nephropathy or severe glomerulopathy on biopsy, the kidneys may remain large. Thus, renal size does not indicate the severity of diabetic renal lesions on biopsy.

Key words: Kidney size, diabetic nephropathy, creatinine clearance, mesangium, glomerular basement membrane, urinary albumin excretion, hypertension, Type 1 diabetes.
Nephropathy is a major complication of diabetes mellitus and results in renal failure in at least one-third of Type 1 diabetic patients within 15-30 years of the onset of the disease $[1,2]$. Usually at diagnosis there are subtle renal functional and structural changes which include elevated glomerular filtration rate (GFR) [3-8], renal plasma flow [3-8], and increased kidney size [3-8]. Within a few years, exercise-induced [9] and resting [10] microalbuminuria are also noted. In newly diagnosed diabetic patients [4] and in patients with duration up to 12 years $[3,6,7]$, a direct relationship has been found between GFR and kidney size measured either by X-ray or by ultrasound. It is not know whether these early abnormalities have any value in predicting whether an individual patient has a relatively increased or decreased risk of the development of overt clinical nephropathy, characterised by Albustix-positive proteinuria, hypertension, and declining GFR, culminating, ultimately, in end-stage renal disease.

In this study, we examined one of the renal parameters in diabetes, kidney size, to determine whether this measure reflects diabetic nephropathy. This was carried out to test if increased kidney size could indicate the degree of diabetic lesions apparent on biopsy. Clinical diabetic nephropathy is always associated with advanced pathological changes of diabetic nephropathy, especially advanced expansion of the glomerular mes- angium [11]. However, since severe diabetic glomerular lesions can be developing in the absence of overt clinical manifestations, it was hoped that measurement of kidney size could be a non-invasive and inexpensive indicator of this group of patients.

\section{Subject and methods}

\section{Subjects}

Thirty-five Type 1 diabetic patients were evaluated at the Clinical Research Center of the University of Minnesota. These patients had a mean $\pm S D$ age of $30 \pm 9$ years (range 9-52 years). The mean duration of diabetes was $18 \pm 7$ years (range 2.5-29 years). Each patient had at least two and usually three 24-h urine collections for creatinine clearance (corrected up to $1.73 \mathrm{~m}^{2}$ ) and for urinary albumin excretion measured by nephelometry using the Beckman immunochemistry system [12] and multiple blood pressure readings. Overt clinical nephropathy was defined as the presence of two or more of the following criteria: urinary albumin excretion in excess of $400 \mathrm{mg} / 24 \mathrm{~h}$, hypertension with blood pressure above $140 / 90 \mathrm{mmHg}$ or on anti-hypertensive treatment, and creatinine clearance $<95 \mathrm{ml} / \mathrm{min}$ per $1.73 \mathrm{~m}^{2}$. Thirteen subjects were thus defined as having clinical nephropathy. Of the remaining 22 patients, all had a creatinine clearance $>95 \mathrm{ml} / \mathrm{min}$ per $1.73 \mathrm{~m}^{2}$, had urinary albumin excretion $<200 \mathrm{mg} / 24 \mathrm{~h}$, and were normotensive with the exception of one patient who was thought to have essential hypertension. Following intravenous pyelography, a percutaneous renal biopsy was performed. The patients reported here are part of a group of 43 consecutive diabetic patients who were either 


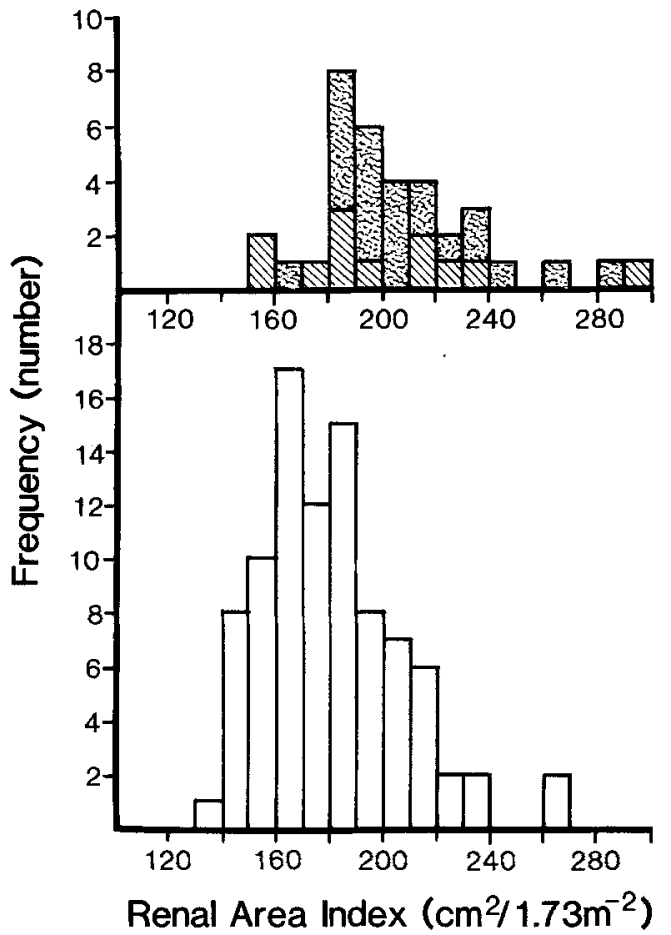

Fig.1. Frequency distribution of kidney size in normal and diabetic subjects $\square$ normal subjects; diabetic subjects with clinical nephropathy; diabetic subjects without clinical nephropathy)

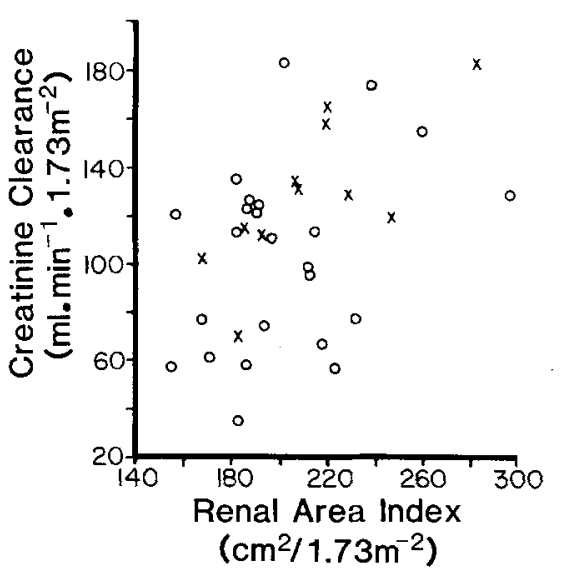

Fig. 2. Relationship between creatinine clearance and kidney size $(r=+0.43, p<0.05)$. ( $x)$ patients with duration of diabetes $<15$ years; $O$ patients with duration of diabetes $>15$ years

evaluated for possible pancreas transplantation or prior to being placed on a strict metabolic control protocol and whose renal biopsy results have been reported in detail elsewhere [11]. All subjects of this earlier group who had intravenous pyelographic measurement of kidney size were included; the subjects not included in the group reported here consisted of six patients who did not have an intravenous pyelogram or whose $\mathrm{X}$-rays were lost, one with a single kidney and one with chronic pyelonephritis. One patient included here had a renal biopsy before being placed on a strict glycaemic control regimen. The protocol was approved by the Committee for the Use of Human Subjects in Research of the University of Minnesota, and informed consent was obtained from each patient or responsible parent.

Out of 118 consecutive living-related kidney donors participating in the renal transplant programme at the University of Minnesota, 90 had renal arteriography available and served as normal subjects. These normal subjects had an average age of $33 \pm 14$ years (range
16-63 years). Intravenous pyelography and renal arteriography were performed during their evaluation as kidney donors. Each gave permission for a renal biopsy to be performed at the time of transplant.

\section{Kidney size}

The length and width of each kidney was determined as described by Moell [13] on a nephrotomogram obtained at $10 \mathrm{~min}$ following contrast injection in the diabetic patients, where length of the kidney was defined as the greatest distance between the upper and lower poles and the width of the kidney was defined as the greatest distance between tangent lines to the most lateral and medial parts of the kidney perpendicular to the length. The length and width obtained from intravenous pyelograms in 15 of the normal subjects were identical to those obtained from the renal arteriograms in these same subjects. These arteriograms were used therefore for measurements because the much denser nephrograms obtained with this procedure allowed the measurements to be performed far more quickly. Renal area index was defined as length $\times$ width of the right kidney plus length $x$ width of the left kidney expressed as $\mathrm{cm}^{2} / 1.73 \mathrm{~m}^{2}$ body surface area [14]. Body surface area was estimated using the equation of Dubois and Dubois [15].

\section{Tissue preparation}

Part of each biopsy specimen was fixed in Zenker's solution, washed, and embedded in paraffin. This tissue was then cut into $2 \mu$ sections and stained with periodic acid-Schiff. The remainder of the tissue was fixed in $2.5 \%$ gluteraldehyde in $0.17 \mathrm{~mol} / 1$ cacodylate buffer and prepared for electron microscopy as described previously [16].

\section{Light microscopy}

The index of mesangial thickening was determined on coded specimens as described $[11,17]$. An average of 25 glomeruli per biopsy were observed.

\section{Electron microscopy}

At least three glomeruli from each patient were examined. Glomerular basement membrane width was determined using the orthogonal intercept method of Gundersen et al. [18]. The glomerular tuft area was defined by a minimal string polygon [19]. Percentage total mesangium, defined as the percentage of the glomerular tuft area occupied by mesangial matrix and cells, was then determined by point counting techniques as described previously [16]. The high correlation that we have found between the index of mesangial thickening, as determined by light microscopy of relatively large numbers of glomeruli, and the electron microscopic measurement of percentage total mesangium [11], based on a much smaller glomerular sample size $(r=0.94$, $p<0.0005$ ), indicated that a correct and independent sampling of glomeruli for electron microscopy has been used. The values for normal subjects reported here did not differ from the previously reported normal values where glomerular basement membrane width was greater in males than females ( $373 \pm 42$ versus $326 \pm 45 \mathrm{~nm}$ ) [20]. As previously reported, percentage total mesangium was not significantly different between normal males and females with a mean of $14.2 \pm$ $4.1 \%[20]$.

\section{Statistical methods}

We used the method of least squares linear regression analysis and Student's t-test.

\section{Results}

In normal subjects the renal area index, which averaged $180 \pm 25 \mathrm{~cm}^{2} / 1.73 \mathrm{~m}^{2}$, was similar in both sexes, and did not correlate with age. The mean renal area index of 


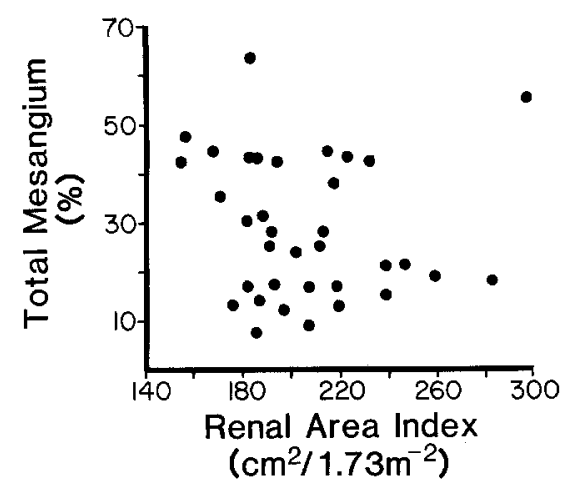

Fig. 3. Relationship between percentage total mesangium and kidney size in the diabetic subjects

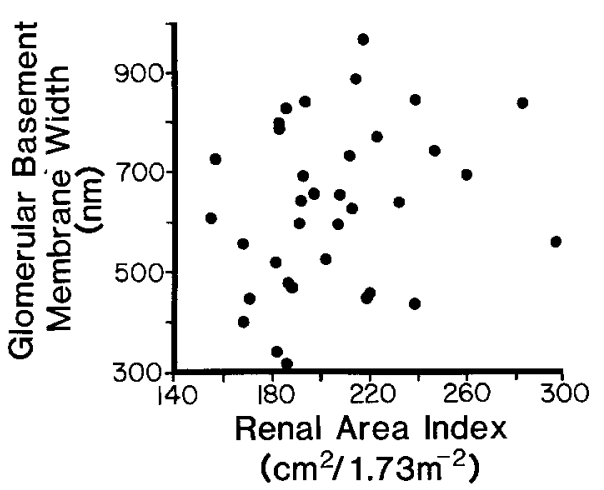

Fig. 4. Relationship between glomerular basement membrane width and kidney size in the diabetic subjects

$206 \pm 32 \mathrm{~cm}^{2} / 1.73 \mathrm{~m}^{2}$ in the diabetic patients was greater than that in normal subjects (Fig. $1 ; p<0.001$ ). In the 13 subjects with clinical nephropathy, the renal area index averaged $199 \pm 39 \mathrm{~cm}^{2} / 1.73 \mathrm{~m}^{2}$, while in the $22 \mathrm{sub}$ jects without clinical nephropathy, the renal area index averaged $210 \pm 29 \mathrm{~cm}^{2} / 1.73 \mathrm{~m}^{2}(t=0.98$, NS). In the diabetic patients, the renal area index correlated with creatinine clearance $(r=0.43, p<0.05$, Fig. 2$)$, particularly when only those patients with duration of diabetes $<15$ years were considered $(r=0.72, p<0.001)$. The renal area index did not correlate with duration of diabetes, urinary albumin excretion, percentage total mesangium (Fig. 3) or glomerular basement membrane width (Fig. 4).

\section{Discussion}

The methods for kidney size determination in clinical studies have included contrast and non-contrast radiological measurement and ultrasound examination. Good correlations have been found between kidney size measured both by X-ray methods and by ultrasound and actual kidney weight at autopsy [13, 23, 24]. Certainly, contrast administration and positioning of the patient may affect the actual measurements ob- tained by X-rays [23]. The kidney size measurements reported here are not used to determine absolute kidney weight, but to compare diabetic patients with normal subjects and within the diabetic group to compare subjects with a range of structural and functional abnormalities.

Renal enlargement has been reported both in diabetic patients [3-8] and in experimental diabetic animals [21, 22]. Despite a broad spectrum of structural and clinical diabetic glomerulopathy, mean kidney size in our patients was larger than in normal subjects. Renal hypertrophy has been shown to correlate with the increased glomerular filtration rate in newly diagnosed diabetic subjects and in diabetic patients with up to 12 years of disease $[3,4,6,7]$. Our data confirm this correlation between kidney size and GFR, especially in the first 15 years of diabetes. However, kidney size did not correlate with the duration of diabetes, or the biopsy findings of glomerular basement membrane width and relative mesangial volume. Thus, the kidneys may remain large in patients with nephropathy demonstrated either by clinical manifestations or by advanced glomerulopathy on biopsy. Certainly, knowledge of renal size does not add to the evaluation of the patient as to the severity of the underlying renal lesions since large kidneys may be associated with minor or severe structural abnormalities.

Acknowledgements. This work was supported in part from NIH grant AM16797, the Juvenile Diabetes Foundation and the Minnesota Medical Foundation. E. N.E. was supported by U.S. Public Health Service Training Grant AM07087. We thank the patients for their generous and courageous contributions to this work. We appreciate the valuable assistance of the staff of the Clinical Research Center. We thank Mr. M. Hoff for medical arts and graphics and Ms. C. Dawis for typing the manuscript. We thank L.Seaquist, R.N., for her careful measurements of kidney size and $J$. Basgen for his excellent work in electron microscopy.

\section{References}

1. Knowles HC Jr, Guest GM, Lampe J, Kessler M, Skillman TG (1965) The course of juvenile diabetes treated with unmeasured diet. Diabetes 14: 239-273

2. Deckert T, Poulsen J, Larsen M (1976) Prognosis in juvenile diabetes mellitus. Acta Endocrinol 203 (Suppl 82): 15 (Abstract)

3. Mogensen CE, Andersen MJF (1973) Increased kidney size and glomerular filtration rate in early juvenile diabetes. Diabetes 22 : 706-712

4. Mogensen CE, Andersen MJF (1975) Increased kidney size and glomerular filtration rate in untreated juvenile diabetes: normalization by insulin treatment. Diabetologia 11:221-224

5. Christiansen JS, Gammelgaard J, Tronier B, Svendsen PA, Parving HH (1982) Kidney function and size in diabetics before and during initial insulin treatment. Kidney Int 21: 683-688

6. Puig JG, Anton FM, Grande C, Pallardo LF, Arnalich F, Gil A, Vasquez JJ, Garcia AM (1981) Relation of kidney size to kidney function in early insulin-dependent diabetes. Diabetologia 21: $363-367$

7. Christiansen JS, Gammelgaard J, Frandsen M, Parving HH (1981) Increased kidney size, glomerular filtration rate and renal plasma flow in short-term insulin-dependent diabetes. Diabetologia 20: $451-456$ 
8. Wiseman M, Viberti GC (1983) Kidney size and glomerular filtration rate in Type 1 (insulin-dependent) diabetes mellitus revisited. Diabetologia 25: 530 (Letter)

9. Mogensen CE (1976) Renal function changes in diabetes. Diabetes 25 (Suppl 2): 872-879

10. Viberti GC, Pickup JC, Jarrett RJ, Keen H (1979) Effect of control of blood glucose on urinary excretion of albumin and beta 2-microglobulin in insulin-dependent diabetics. $\mathbf{N}$ Engl $\mathbf{J}$ Med 300: 638-641

11. Mauer SM, Steffes MW, Sutherland DER, Brown DM, Goetz FC (1984) Structural-functional relationships in diabetic nephropathy. J Clin Invest 4: 1143-1155

12. Killingworth LM, Savory J (1974) Nephelometric methods for the determination of albumin, transferrin, and alpha 2-macroglobulin. Ann Clin Lab Sci 4: 46-52

13. Moell H (1961) Kidney size and its deviation from normal in acute renal failure. Acta Radiol 206 (Suppl): 4-74

14. Andersen MJF, Mogensen CE (1973) Relationship between renal size and function in normal subjects. Acta Radiol Diag 14: 209-214

15. Dubois D, Dubois EF (1916) Clinical calorimetry. A formula to estimate the approximate surface area if height and weight be known. Arch Intern Med 17: 863-871

16. Steffes MW, Brown DM, Basgen JM, Mauer SM (1980) Amelioration of mesangial volume and surface alterations following islet transplantation in diabetic rats. Diabetes 29:509-515

17. Mauer SM, Steffes MW, Sutherland DER, Najarian JS, Michael AF, Brown DM (1975) Studies of the rate of regression of the glomerular lesion in diabetic rats treated with pancreatic islet transplantation. Diabetes 24: 280-285
18. Jensen EB, Gundersen HJG, Østerby R (1979) Determination of membrane thickness distribution from orthogonal intercepts. $J$ Microsc 115: 19-33

19. Østerby R, Gundersen HJG (1980) Fast accumulation of basement membrane material and the rate of morphologic changes in acute experimental diabetic glomerular hypertrophy. Diabetologia 18: 493-500

20. Steffes MW, Barbosa J, Basgen JM, Sutherland DER, Najarian JS, Mauer SM (1983) Quantitative glomerular morphology of the normal human kidney. Lab Invest 49: $82 \ldots 86$

21. Seyer-Hansen K (1976) Renal hypertrophy in streptozotocin-diabetic rats. Clin Sci Mol Med 51: 551-555

22. Seyer-Hansen K, Hansen J, Gundersen HJG (1980) Renal hypertrophy in experimental diabetes. Diabetologia 18: 501-505

23. Abrams HL (1972) Quantitative derivates of renal radiologic studies. Invest Radiol 7: 240-279

24. Rasmussen SN, Haase L, Kjeldsen H, Hancke S (1978) Determination of renal volume by ultrasound scanning. J Clin Ultra 6 : 160-164

Received: 9 May 1984

and in revised form: 23 October 1984

Dr. S. M. Mauer

Department of Pediatrics

University of Minnesota

Box 491, Mayo Memorial Building

420 Delaware Street SE

Minneapolis, MN 55455

USA 